Article

\title{
Screening-Level Risk Assessment of a Hydrogen Refueling Station that Uses Organic Hydride
}

\author{
Kiyotaka Tsunemi *D, Kikuo Yoshida, Takehiro Kihara, Tei Saburi and Kyoko Ono
}

Research Institute of Science for Safety and Sustainability, National Institute of Advanced Industrial Science and Technology, Tsukuba, Ibaraki 305-8569, Japan; k-yoshida@aist.go.jp (K.Y.); t-kihara@aist.go.jp (T.K.);

t.saburi@aist.go.jp (T.S.); kyoko.ono@aist.go.jp (K.O.)

* Correspondence: k-tsunemi@aist.go.jp; Tel.: +81-29-861-3984

Received: 31 October 2018; Accepted: 20 November 2018; Published: 28 November 2018

\begin{abstract}
This study involves a screening-level risk assessment of the impairment of human health and life related to hydrogen explosion and chemical release during the operation of a hydrogen refueling station (HRS) that uses organic hydride. First, twenty-one accident scenarios were identified involving the leakage of hydrogen, toluene and methylcyclohexane (MCH) in the HRS. Next, the leakage frequency for each scenario was estimated using a hierarchical Bayesian model. Simulations were then performed of the blast-wave pressure and heat radiation after a hydrogen leak and of atmospheric dispersion of evaporated chemicals after leaks of liquid $\mathrm{MCH}$ and toluene. The consequences were estimated for each scenario according to leak size using the existing probit functions and threshold values. Finally, the risk due to explosion, heat radiation, and acute toxicity was estimated by multiplying the consequence by the leakage frequency. The results show that the mortality risk of explosion and acute effect is less than $10^{-6}$ per year, which is a negligible level of concern. However, the mortality risk of heat radiation in the scenarios involving hydrogen leakage from the pipe connected to the cylinders and compressors exceeds $10^{-4}$ per year inside the HRS, thereby requiring additional steps if a more-detailed risk assessment is needed.
\end{abstract}

Keywords: hydrogen refueling station; organic hydride; quantitative risk assessment; explosion; heat radiation; acute toxicity

\section{Introduction}

Fuel cell vehicles (FCVs) have the potential both to reduce considerably our dependence on foreign oil and to lower harmful emissions that contribute to air pollution. There are now growing numbers of FCVs and hydrogen refueling stations (HRSs) globally. Hydrogen has major characteristic hazards such as explosion and embrittlement, which increases the accidental risks at HRSs. To prevent and mitigate major hydrogen accidents, adequate safety measures should be identified through risk assessment [1]. Therefore, research has been conducted into quantifying the potential risk related to HRSs.

Li et al. [2] performed a quantitative risk assessment (QRA) based on thirteen accident scenarios involving jet fires, flash fires, and explosions at high-pressure HRSs. They reported that the individual risk in an HRS is $6.48 \times 10^{-4}$ per year, and leaks from compressors and dispensers are the main risk contributors. Sun et al. [3] performed a risk analysis based on nine accident scenarios involving jet fires and flash fires at high-pressure HRSs. They found that the individual risk in a refueling station is $7.65 \times 10^{-6}$ per year. The leak from booster compressors contributes the most to the overall risks, almost $69 \%$, and the leak from tube storages contributes the second most to the overall risks, approximately $27 \%$. Furthermore, the individual risk to customers was $1.63 \times 10^{-5}$ per year. 
LaChance [4] described an application of QRA methods to help establish the minimum separation distance between an HRS and the public. Kikukawa et al. [5] undertook a screening-level risk assessment of HRSs for 70-MPa FCVs and suggested that a safety distance of $6 \mathrm{~m}$ was sufficient in such cases.

The organic chemical hydride method for hydrogen storage and transportation has both high gravimetric and volumetric hydrogen density. However, this method has not been established technically, because a dehydrogenation catalyst has not attained enough stability or sufficient performance [6]. Thus, this method for hydrogen storage using hydrogenation and dehydrogenation chemical reactions has been developing recently. Okada et al. [7] developed a dehydrogenation catalyst using a simple fixed-bed reactor that has a high stability and sufficient performance. Biniwale et al. [8] studied thermal profile of catalysts surface under spray-pulsed injection of cyclohexane over $\mathrm{Pt}$ catalysts supported on activated carbon and alumite. Shukla et al. [9] described the results of experiments on dehydrogenation of methylcyclohexane $(\mathrm{MCH})$ over Pt supported on metal oxides (Pt/MO) and $\mathrm{Pt}$ supported on perovskite.

This organic chemical hydride method is considered low potential risk, because hydrogen is stored as a chemical liquid under ambient pressure at room temperature [6]. Tsunemi et al. [10] estimated the consequences and damage due to explosions and heat radiation after a hydrogen leak, as well as the acute toxicity caused by the leakage and dispersion of $\mathrm{MCH}$ and toluene energy carriers in an HRS that uses organic hydride. However, there are no existing studies involving the risk assessment of HRS using organic hydride considering the frequency of leakage accidents at the station. The aim of this study was to conduct a screening-level assessment to identify and quantify the risk of impairment to human health and life related to hydrogen explosions and chemical release during the operation of an HRS that uses organic hydride.

\section{Materials and Methods}

A risk assessment framework for an HRS was constructed, as shown in Figure 1, to include accident probabilities, emissions of chemical substances, hazards, vulnerabilities, and exposure. Risk assessment is based on various assumptions, thus it is important to refine scenarios whose risk is a high level of concern at the screening-level assessment. In this study, a screening-based risk assessment was conducted by calculating the largest hazard for all leakage accident scenarios and the leak size of hydrogen and chemicals.

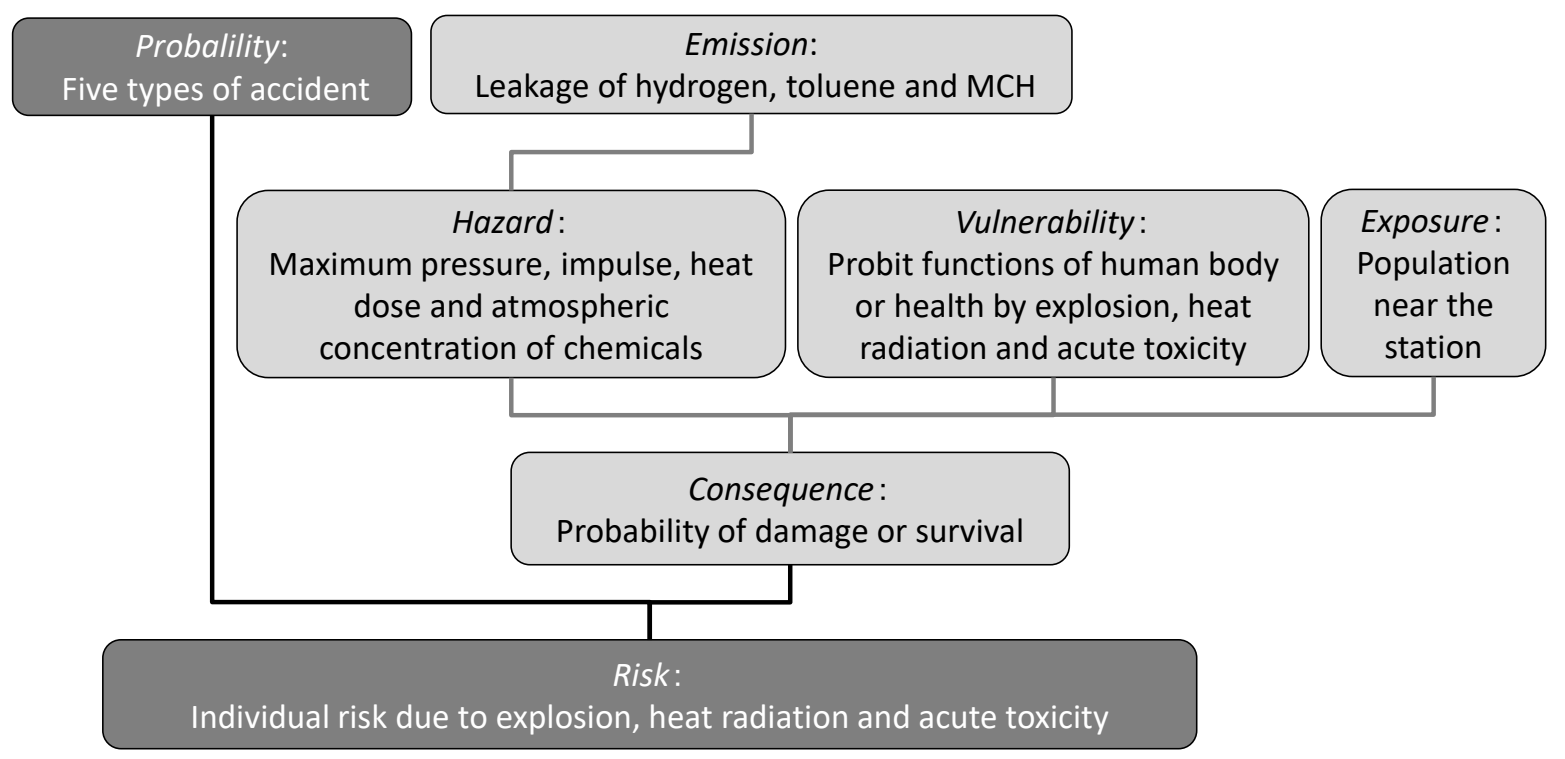

Figure 1. Risk assessment framework for a hydrogen refueling station. 
The characteristics of this assessment are as follows. First, operational occurrences and accidents due to various components and devices in the station were treated totally for screening assessment. Second, a method for estimating the leakage frequency using a hierarchical Bayesian model was established to use an existing accident database as the prior distribution, updated by incorporating the data for HRS accidents. Third, in addition to the effects of explosions and heat, the effects of the toxicities of the leaked chemicals were turned into risk assessment objects for application to an HRS that uses organic hydride. Fourth, the spatial distribution of human risk, including residents living near the HRS, was estimated and displayed using a geographic information system (GIS).

\subsection{Leakage Scenarios}

We assumed that an HRS that uses organic hydride is located in inner Tokyo where the population density is high. An organic hydride HRS uses three main processes (Figure 2). For liquid storage, $\mathrm{MCH}$ (the hydrogen energy carrier) is pumped from a tanker truck into the HRS storage tank. Toluene (the byproduct of dehydrogenation) is stored before being removed from the HRS. During dehydrogenation, the hydrogen is separated from the $\mathrm{MCH}$ and refined. For hydrogen storage, the refined hydrogen is compressed and stored in storage cylinders, from where it is sent to the dispenser to supply FCVs.

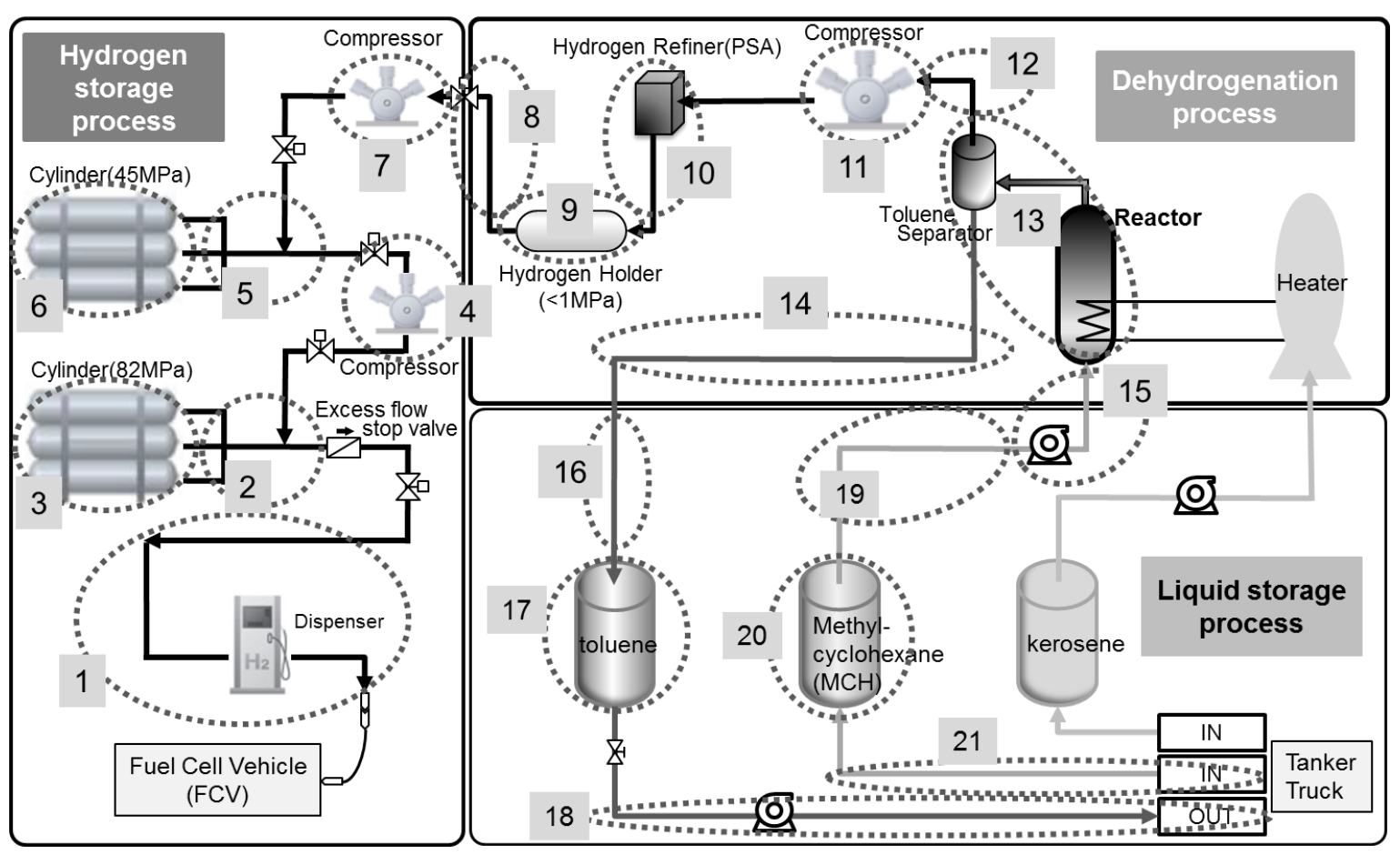

Figure 2. Schematic flow and leakage scenarios of a hydrogen refueling station that uses organic hydride.

We created twenty-one scenarios involving leakage from components (Figure 2) based on hypothetical accidents in which either hydrogen leaked from the hydrogen storage pipes or $\mathrm{MCH}$ or toluene leaked from the liquid storage pipes in the HRS. Following LaChance et al. [11], we categorized the leak sizes as: "very small", "minor", "medium", "major", and "rupture". These correspond to ratios of the leak hole area to the total flow area of $0.01 \%, 0.1 \%, 1 \%, 10 \%$, and $100 \%$, respectively. Hereinafter, we refer to the fractional leak area as FLA.

\subsection{Leakage Frequency}

The data on HRS accidents are limited, and there are no such data for organic hydride HRSs because such stations are yet to be operational. Therefore, it is difficult to estimate leak frequencies 
or accident rates appropriately using exiting leakage/accident data. Instead, we estimated the leak frequencies for hydrogen, $\mathrm{MCH}$, and toluene by using the method of Kihara et al. involving a Bayesian inference model [12], for which we followed the method of LaChance et al. [11]. Table 1 describes the data used for Bayesian updating. These come in the form of leak frequencies observed in the chemical, compressed-gas, nuclear-power, and offshore petroleum industries and from HRSs in the US, as well as accident records for compressed natural gas stations, HRSs, and gasoline stations in Japan. While the US accident database records leak frequencies, the Japanese one records narrative descriptions of accidents rather than leak frequencies or accident rates. Therefore, we classified each accident record datum according to the FLA criteria and calculated the leak frequency per component.

Table 1. Accident database used to estimate leakage frequency.

\begin{tabular}{lll}
\hline \multicolumn{1}{c}{ Description of Accident Database } & Processes Applied & References \\
\hline $\begin{array}{l}\text { Accidents recorded during 1975-2007 in the US for } \\
\text { the chemical-processing, compressed-gas, } \\
\text { nuclear-power, and offshore-petroleum industries } \\
\text { and hydrogen refueling stations. }\end{array}$ & $\begin{array}{l}\text { Hydrogen storage, } \\
\text { dehydrogenation, liquid storage }\end{array}$ & $\begin{array}{l}\text { Sandia National Laboratories, } \\
2009,2012 \text { [11,13] }\end{array}$ \\
\hline $\begin{array}{l}\text { 637 accidents during 1965-2015 in Japan for } \\
\text { compressed natural gas stations and hydrogen } \\
\text { refueling stations. }\end{array}$ & $\begin{array}{l}\text { Hydrogen storage, } \\
\text { dehydrogenation }\end{array}$ & $\begin{array}{l}\text { High Pressure Gas Safety Institute } \\
\text { of Japan [14] }\end{array}$ \\
\hline $\begin{array}{l}\text { 869 accidents during 2006-2014 in Japan for } \\
\text { gasoline stations. }\end{array}$ & Liquid storage & $\begin{array}{l}\text { Fire and Disaster Management } \\
\text { Agency, Japan [15] }\end{array}$ \\
\hline
\end{tabular}

The inference model assumes that the logarithm of the mean leak frequency for each component is related linearly to the logarithm of the FLA [11]. We constructed a linear regression model, for which we used a hierarchical Bayesian model in parts. We then used WinBUGS version 1.4.3 [16] to obtain the most likely parameter values and the mean and credible intervals of leak frequency for each FLA. We assumed that the distribution of leak frequency on the FLA follows a log-normal distribution. Considering the components listed in Table 2, we obtained the leak frequencies for the component assembly for the twenty-one leakage scenarios and five FLAs.

We used the median of the estimated leak frequency for following assessment. Upon hydrogen leakage, we assumed inevitable ignition as the worst-case scenario for the screening assessment, which is why the accident probability is the same as the leak frequency. 
Table 2. Assumed numbers of components in each leakage scenario.

\begin{tabular}{|c|c|c|c|c|c|c|c|c|c|c|c|c|c|c|}
\hline No. ${ }^{1}$ & Leakage Scenario & Pipes & Joints & Valves & Flanges & Compressors & Pumps & Cylinders & Tanks & Reactors & $\begin{array}{l}\text { Hydrogen } \\
\text { Refiner }\end{array}$ & Hoses & $\begin{array}{l}\text { Nozzles } \\
\text { and } \\
\text { Couplers }\end{array}$ & Inlet/Outlet \\
\hline 1 & $\begin{array}{l}\text { Components associated with dispenser (excess-flow } \\
\text { stop valve, dispenser nozzle) }\end{array}$ & 80 & 40 & 10 & & & & & & & & 8 & 2 & \\
\hline 2 & Components connected to cylinder ( $82 \mathrm{MPa}$ ) & 5 & 20 & 15 & & & & & & & & & & \\
\hline 3 & Cylinder (82 MPa, $300 \mathrm{~L})$ & & & & & & & 3 & & & & & & \\
\hline 4 & Compressor $(82 \mathrm{MPa})$ and related components $(50 \mathrm{~L})$ & 20 & 30 & 5 & & 1 & & & & & & & & \\
\hline 5 & Components connected to cylinder ( $45 \mathrm{MPa}$ ) & 5 & 20 & 15 & & & & & & & & & & \\
\hline 6 & Cylinder (45 MPa, $300 \mathrm{~L})$ & & & & & & & 9 & & & & & & \\
\hline 7 & Compressor $(45 \mathrm{MPa})$ and related components $(50 \mathrm{~L})$ & 20 & 30 & 5 & & 1 & & & & & & & & \\
\hline 8 & Components connected to hydrogen holder $(300 \mathrm{~L})$ & 30 & 20 & 8 & & & & & & & & & & \\
\hline 9 & Hydrogen holder (1 MPa, $300 \mathrm{~L})$ & & & & & & & 1 & & & & & & \\
\hline 10 & Hydrogen refiner and related components & 20 & 30 & 10 & & & & & & & 1 & & & \\
\hline 11 & Compressor in dehydrogenation process & 10 & 30 & 5 & & 1 & & & & & & & & \\
\hline 12 & Components connected to toluene separator & 20 & 30 & 5 & & & & & & & & & & \\
\hline 13 & $\begin{array}{l}\text { Dehydrogenation reactor and related components } \\
(0.3 \mathrm{MPa}, 1800 \mathrm{~L})\end{array}$ & 20 & 50 & 10 & 7 & & & & & 1 & & & & \\
\hline 14 & Toluene return piping and related components & 5 & & 1 & 3 & & & & & & & & & \\
\hline 15 & $\begin{array}{l}\text { Methylcyclohexane }(\mathrm{MCH}) \text { feed piping and related } \\
\text { components }\end{array}$ & 5 & & 1 & 5 & & 1 & & & & & & & \\
\hline 16 & Toluene return piping (underground piping) & 5 & & & & & & & & & & & & \\
\hline 17 & Toluene storage tank (underground tank, $30 \mathrm{~m}^{3}$ ) & & & & & & & & 1 & & & & & \\
\hline 18 & Components for removing toluene & 17 & & 2 & 7 & & 1 & & & & & 3 & & 1 \\
\hline 19 & $\mathrm{MCH}$ feed piping & 5 & & & & & & & & & & & & \\
\hline 20 & $\mathrm{MCH}$ storage tank (underground tank, $30 \mathrm{~m}^{3}$ ) & & & & & & & & 1 & & & & & \\
\hline 21 & Components for receiving $\mathrm{MCH}$ & 16 & & 1 & 3 & & & & & & & 3 & & 1 \\
\hline
\end{tabular}




\subsection{Emissions and Hazards}

We calculated the amount of leaked hydrogen for each FLA assuming that: (i) hydrogen (at a maximum pressure of $82 \mathrm{MPa}$ ) begins leaking from the hydrogen storage pipes (with an inner diameter of $5.9 \mathrm{~mm}$ ); (ii) the shut-off valve activates after $30 \mathrm{~s}$ [9]; and (iii) the excess-flow stop valve operates within $0.2 \mathrm{~s}$ if the flow rate of hydrogen exceeds $3.6 \mathrm{~kg} / \mathrm{min}$ [17]. We calculated the leaked amounts of toluene and $\mathrm{MCH}$ for each FLA by assuming an inner pipe diameter of $27.6 \mathrm{~mm}$ in the liquid storage process, an inner pipe diameter of $105.3 \mathrm{~mm}$ for removing toluene and receiving $\mathrm{MCH}$, and continuous chemical leakage for $30 \mathrm{~min}$ [10].

We assumed that the total amount of hydrogen leaked for $30 \mathrm{~s}$ forms a stoichiometric hydrogen/air mixture (30 vol \%). An ignition point was set at the horizontal center of the mixture region and $0.5-1 \mathrm{~m}$ above the ground, and the value of ignition probability was set to $100 \%$. The ignition results in a premixed hydrogen/air explosion which will be the largest hazard. We used FLACS and FLACS-Fire (GexCon) software to estimate the blast-wave pressure, impulse, and heat from the hydrogen leak at each grid point and time.

We estimated the average concentrations of chemicals in the atmosphere within each 10-m mesh $30 \mathrm{~min}$ after the chemicals began to leak. For this, we used the frequencies of wind direction, wind speed, and atmospheric stability for the meteorological conditions in Tokyo using a puff model incorporated in the Acute Effect Assessment Tool under development by the National Institute of Advanced Industrial Science and Technology [18].

Grid points for analysis were arranged at intervals of around $10 \mathrm{~m}$ in an area with a radius of $200 \mathrm{~m}$ from the hydrogen ignition point or $100 \mathrm{~m}$ from the chemical leak source at a height of $1.5 \mathrm{~m}$ above the ground.

\subsection{Vulnerability and Consequence}

We used the probit functions from the Green Book $[19,20]$ to estimate the consequences of exposure to the blast-wave pressure, namely eardrum rupture, fatalities caused by being displaced by the blast wave, and fatalities caused by head injuries. We used the same method to estimate the consequences of the heat dose, namely first-degree burns, second-degree burns, and fatalities.

We used the acute exposure guideline levels (AEGL) are the airborne concentration of a substance above which it is predicted that the general population could experience life-threatening health effects or death (AEGL-3); irreversible or other serious, long-lasting adverse health effects or an impaired ability to escape (AEGL-2); and notable discomfort, irritation, or certain asymptomatic non-sensory effects (AEGL-1) [21]. We used AEGLs for 30-min inhalation exposure to toluene of $250 \mathrm{mg} / \mathrm{m}^{3}$ (AEGL-1), $2900 \mathrm{mg} / \mathrm{m}^{3}$ (AEGL-2), and 20,000 mg/m³ (AEGL-3) [22], and used the AEGL-1 equivalent human NOAEL for MCH acute effect of $690 \mathrm{mg} / \mathrm{m}^{3}$ [10] for threshold values.

The consequence of acute inhalation toxicity through inhalation of $\mathrm{MCH}$ or toluene was estimated by aggregating the probabilities of the various meteorological conditions when the atmospheric chemical concentration exceeds each of the above threshold values.

\subsection{Damage and Risk}

To calculate the number of injuries in the HRS and among the surrounding residents due to an HRS accident, we constructed 10-m mesh GIS data for the populations inside the buildings [9]. We calculated the damage $D_{i}$ for each leakage scenario by multiplying the population by the consequence from each 10-m mesh estimated in Section 2.4 for each leak size:

$$
D_{i}=\Sigma_{j}\left(C_{i, j} \times P_{o p}\right)
$$

where $D_{i}$ (number of people) is the damage due to an accident with leak size $i, C_{i, j}(-)$ is the consequence of 10-m mesh $j$ due to an accident with leak size $i$, and $P o p_{j}$ (number of people) is the population in 
$10-\mathrm{m}$ mesh $j$. We estimated the individual risk $I R_{j}$ for each leakage scenario due to explosion, heat radiation, and acute toxicity by multiplying the consequence by the probability for each leak size:

$$
I R_{j}=\Sigma_{j}\left(C_{i, j} \times \operatorname{Prob}_{i}\right),
$$

where $I R_{j}$ is the individual risk of $10-\mathrm{m}$ mesh $j$ and $\operatorname{Prob}_{i}(-)$ is the probability of each leakage scenario for leak size $i$. We calculated the population risk $P R$ for each leakage scenario by multiplying the individual risk of each 10-m mesh by the population of each 10-m mesh:

$$
P R=\Sigma_{j}\left(I R_{j} \times P o p_{j}\right)
$$

\section{Results}

\subsection{Leakage Frequency and Emission}

Table 3 lists the results for the estimated leak frequencies and emissions of hydrogen, $\mathrm{MCH}$, and toluene for the 21 scenarios and the five FLAs. In Scenarios 1, 2, 4, 5, 7 and 10-13, the leakage frequency exceeds $10^{-2}$ per year. Those results arise from the high estimated leakage frequencies of the hoses, nozzles and couplers, and compressors. The emissions exceed $100 \mathrm{~m}^{3}$ in Scenarios 2, 3, 5 and 6 because of the large stored quantities of hydrogen with high pressure.

Table 3. Results for leak frequencies of processes and emissions of hydrogen and energy carriers for 21

\begin{tabular}{|c|c|c|c|c|c|c|c|c|c|c|}
\hline \multirow{2}{*}{$\begin{array}{l}\text { Leakage } \\
\text { Scenario }\end{array}$} & \multicolumn{5}{|c|}{ Frequency $^{1}$} & \multicolumn{5}{|c|}{ Emission $^{2}$} \\
\hline & $\begin{array}{l}\text { Very } \\
\text { Small }\end{array}$ & Minor & Medium & Major & Rupture & $\begin{array}{l}\text { Very } \\
\text { Small }\end{array}$ & Minor & Medium & Major & Rupture \\
\hline 1 & $8.8 \times 10^{-2}$ & $3.0 \times 10^{-2}$ & $1.2 \times 10^{-2}$ & $5.2 \times 10^{-3}$ & $2.9 \times 10^{-3}$ & 0 & 0.5 & 5 & 1.2 & 4 \\
\hline 2 & $1.0 \times 10^{-2}$ & $5.5 \times 10^{-3}$ & $2.8 \times 10^{-3}$ & $1.3 \times 10^{-3}$ & $1.2 \times 10^{-3}$ & 0 & 0.5 & 5 & 43 & 208 \\
\hline 3 & $9.8 \times 10^{-7}$ & $8.3 \times 10^{-7}$ & $5.6 \times 10^{-7}$ & $3.2 \times 10^{-7}$ & $1.7 \times 10^{-7}$ & 106 & 242 & 243 & 243 & 243 \\
\hline 4 & $1.7 \times 10^{-2}$ & $9.8 \times 10^{-3}$ & $5.5 \times 10^{-3}$ & $3.3 \times 10^{-3}$ & $2.4 \times 10^{-3}$ & 0 & 0.5 & 4 & 28 & 40 \\
\hline 5 & $1.0 \times 10^{-2}$ & $5.3 \times 10^{-3}$ & $2.8 \times 10^{-3}$ & $1.3 \times 10^{-3}$ & $1.2 \times 10^{-3}$ & 0 & 0.3 & 3 & 23 & 114 \\
\hline 6 & $1.0 \times 10^{-5}$ & $8.8 \times 10^{-6}$ & $5.9 \times 10^{-6}$ & $3.4 \times 10^{-6}$ & $1.8 \times 10^{-6}$ & 58 & 133 & 133 & 133 & 133 \\
\hline 7 & $1.7 \times 10^{-2}$ & $9.8 \times 10^{-3}$ & $5.5 \times 10^{-3}$ & $3.3 \times 10^{-3}$ & $2.4 \times 10^{-3}$ & 0 & 0.3 & 2 & 15 & 22 \\
\hline 8 & $8.9 \times 10^{-3}$ & $4.5 \times 10^{-3}$ & $2.3 \times 10^{-3}$ & $1.2 \times 10^{-3}$ & $1.0 \times 10^{-3}$ & 0 & 0 & 0.1 & 0.5 & 3 \\
\hline 9 & $9.8 \times 10^{-7}$ & $8.3 \times 10^{-7}$ & $5.6 \times 10^{-7}$ & $3.2 \times 10^{-7}$ & $1.7 \times 10^{-7}$ & 1 & 3 & 3 & 3 & 3 \\
\hline 10 & $1.3 \times 10^{-2}$ & $6.6 \times 10^{-3}$ & $3.1 \times 10^{-3}$ & $1.5 \times 10^{-3}$ & $1.2 \times 10^{-3}$ & 0 & 0 & 0.1 & 0.3 & 0.5 \\
\hline 11 & $1.7 \times 10^{-2}$ & $9.7 \times 10^{-3}$ & $5.3 \times 10^{-3}$ & $3.2 \times 10^{-3}$ & $2.3 \times 10^{-3}$ & 0 & 0 & 0.1 & 0.3 & 0.5 \\
\hline 12 & $1.1 \times 10^{-2}$ & $5.6 \times 10^{-3}$ & $2.3 \times 10^{-3}$ & $1.1 \times 10^{-3}$ & $7.6 \times 10^{-4}$ & 0 & 0 & 0 & 0.2 & 2 \\
\hline 13 & $2.0 \times 10^{-2}$ & $9.8 \times 10^{-3}$ & $4.2 \times 10^{-3}$ & $1.9 \times 10^{-3}$ & $1.4 \times 10^{-3}$ & 4 & 7 & 7 & 7 & 7 \\
\hline 14 & $3.1 \times 10^{-4}$ & $7.0 \times 10^{-5}$ & $2.1 \times 10^{-5}$ & $1.2 \times 10^{-5}$ & $6.3 \times 10^{-6}$ & 0 & 0 & 0 & 0 & 0.3 \\
\hline 15 & $4.6 \times 10^{-4}$ & $1.6 \times 10^{-4}$ & $5.8 \times 10^{-5}$ & $2.0 \times 10^{-5}$ & $2.0 \times 10^{-5}$ & 0 & 0 & 0.2 & 0.4 & 0.4 \\
\hline 16 & $4.7 \times 10^{-5}$ & $1.8 \times 10^{-5}$ & $7.9 \times 10^{-6}$ & $3.9 \times 10^{-6}$ & $1.6 \times 10^{-6}$ & 0 & 0 & 0 & 0 & 0.3 \\
\hline 17 & $4.5 \times 10^{-5}$ & $1.9 \times 10^{-5}$ & $7.9 \times 10^{-6}$ & $3.3 \times 10^{-6}$ & $1.4 \times 10^{-6}$ & 5 & 29 & 30 & 30 & 30 \\
\hline 18 & $6.7 \times 10^{-3}$ & $4.1 \times 10^{-3}$ & $2.3 \times 10^{-3}$ & $1.3 \times 10^{-3}$ & $8.5 \times 10^{-4}$ & 0 & 0 & 0.2 & 2 & 21 \\
\hline 19 & $4.7 \times 10^{-5}$ & $1.8 \times 10^{-5}$ & $7.9 \times 10^{-6}$ & $3.9 \times 10^{-6}$ & $1.6 \times 10^{-6}$ & 0 & 0 & 0 & 0 & 0.4 \\
\hline 20 & $4.5 \times 10^{-5}$ & $1.9 \times 10^{-5}$ & $7.9 \times 10^{-6}$ & $3.3 \times 10^{-6}$ & $1.4 \times 10^{-6}$ & 5 & 29 & 30 & 30 & 30 \\
\hline 21 & $6.7 \times 10^{-3}$ & $4.1 \times 10^{-3}$ & $2.3 \times 10^{-3}$ & $1.3 \times 10^{-3}$ & $8.5 \times 10^{-4}$ & 0 & 0 & 0.2 & 2 & 21 \\
\hline
\end{tabular}
scenarios and five FLAs.

${ }^{1}$ Unit:/year; values show the median data calculated by Bayesian inference. ${ }^{2}$ Unit: $\mathrm{m}^{3}$ (under standard conditions); chemicals are hydrogen (Scenarios 1-13), MCH (Scenarios 14, 16-18), and toluene (Scenarios 15, 19-21). Total sum value of all 10-m mesh cells for rupture leak.

\subsection{Consequence, Damage and Risk}

Tables 4 and 5 list the results for the consequence, damage, and risk due to explosion and heat radiation, respectively. The consequence, damage and risk due to explosion are low. The individual mortality risk due to explosion is less than $10^{-8}$ per year in Scenarios 1-13. 
Table 4. Results for consequence, damage, and risk to people by explosion.

\begin{tabular}{|c|c|c|c|c|c|c|c|c|c|c|c|c|c|c|c|}
\hline \multirow[t]{2}{*}{ Effect } & \multirow[t]{2}{*}{ Item } & \multirow[t]{2}{*}{ Unit } & \multicolumn{13}{|c|}{ Leakage Scenario } \\
\hline & & & 1 & 2 & 3 & 4 & 5 & 6 & 7 & 8 & 9 & 10 & 11 & 12 & 13 \\
\hline \multirow{4}{*}{$\begin{array}{l}\text { Ruptured ear } \\
\text { drums }\end{array}$} & Consequence, $\max .{ }^{1}$ & $(-)$ & $<10^{-8}$ & $2.0 \times 10^{-5}$ & $1.7 \times 10^{-5}$ & $1.3 \times 10^{-5}$ & $1.3 \times 10^{-5}$ & $1.3 \times 10^{-5}$ & $9.3 \times 10^{-7}$ & $<10^{-8}$ & $<10^{-8}$ & $<10^{-8}$ & $<10^{-8}$ & $<10^{-8}$ & $<10^{-8}$ \\
\hline & Damage $^{2}$ & [people] & $<10^{-8}$ & $4.7 \times 10^{-5}$ & $6.4 \times 10^{-4}$ & $1.1 \times 10^{-4}$ & $3.3 \times 10^{-4}$ & $3.3 \times 10^{-4}$ & $6.7 \times 10^{-6}$ & $<10^{-8}$ & $<10^{-8}$ & $<10^{-8}$ & $<10^{-8}$ & $<10^{-8}$ & $<10^{-8}$ \\
\hline & Individual risk, max. ${ }^{3}$ & [/year] & $<10^{-8}$ & $3.1 \times 10^{-8}$ & $<10^{-8}$ & $5.9 \times 10^{-8}$ & $2.4 \times 10^{-8}$ & $<10^{-8}$ & $<10^{-8}$ & $<10^{-8}$ & $<10^{-8}$ & $<10^{-8}$ & $<10^{-8}$ & $<10^{-8}$ & $<10^{-8}$ \\
\hline & Population risk ${ }^{4}$ & [people/year] & $<10^{-8}$ & $9.5 \times 10^{-7}$ & $<10^{-8}$ & $4.5 \times 10^{-7}$ & $4.7 \times 10^{-7}$ & $<10^{-8}$ & $3.3 \times 10^{-8}$ & $<10^{-8}$ & $<10^{-8}$ & $<10^{-8}$ & $<10^{-8}$ & $<10^{-8}$ & $<10^{-8}$ \\
\hline \multirow{4}{*}{$\begin{array}{l}\text { Blast-wave } \\
\text { fatalities }\end{array}$} & Consequence, max. & $(-)$ & $<10^{-8}$ & $<10^{-8}$ & $<10^{-8}$ & $<10^{-8}$ & $<10^{-8}$ & $<10^{-8}$ & $<10^{-8}$ & $<10^{-8}$ & $<10^{-8}$ & $<10^{-8}$ & $<10^{-8}$ & $<10^{-8}$ & $<10^{-8}$ \\
\hline & Damage & [people] & $<10^{-8}$ & $<10^{-8}$ & $<10^{-8}$ & $<10^{-8}$ & $<10^{-8}$ & $<10^{-8}$ & $<10^{-8}$ & $<10^{-8}$ & $<10^{-8}$ & $<10^{-8}$ & $<10^{-8}$ & $<10^{-8}$ & $<10^{-8}$ \\
\hline & Individual risk, max. & [/year] & $<10^{-8}$ & $<10^{-8}$ & $<10^{-8}$ & $<10^{-8}$ & $<10^{-8}$ & $<10^{-8}$ & $<10^{-8}$ & $<10^{-8}$ & $<10^{-8}$ & $<10^{-8}$ & $<10^{-8}$ & $<10^{-8}$ & $<10^{-8}$ \\
\hline & Population risk & [people/year] & $<10^{-8}$ & $<10^{-8}$ & $<10^{-8}$ & $<10^{-8}$ & $<10^{-8}$ & $<10^{-8}$ & $<10^{-8}$ & $<10^{-8}$ & $<10^{-8}$ & $<10^{-8}$ & $<10^{-8}$ & $<10^{-8}$ & $<10^{-8}$ \\
\hline \multirow{4}{*}{$\begin{array}{l}\text { Head-injury } \\
\text { fatalities }\end{array}$} & Consequence, max. & $(-)$ & 0 & $<10^{-8}$ & $<10^{-8}$ & 0 & 0 & 0 & 0 & 0 & 0 & 0 & 0 & 0 & 0 \\
\hline & Damage & [people] & 0 & 0 & $<10^{-8}$ & 0 & 0 & 0 & 0 & 0 & 0 & 0 & 0 & 0 & 0 \\
\hline & Individual risk, max. & [/year] & 0 & $<10^{-8}$ & 0 & 0 & 0 & 0 & 0 & 0 & 0 & 0 & 0 & 0 & 0 \\
\hline & Population risk & [people/year] & 0 & 0 & 0 & 0 & 0 & 0 & 0 & 0 & 0 & 0 & 0 & 0 & 0 \\
\hline
\end{tabular}

${ }^{1}$ Maximum value of 10-m mesh cell for rupture leak. ${ }^{2}$ Total sum value of all 10-m mesh cells for rupture leak. ${ }^{3}$ Maximum value of 10 -m mesh cell for all leak sizes. ${ }^{4}$ Total sum value of all 10-m mesh cells for all leak sizes.

Table 5. Results for consequence, damage, and risk to people by heat radiation.

\begin{tabular}{|c|c|c|c|c|c|c|c|c|c|c|c|c|c|c|c|}
\hline Effect & Item & Unit & & & & & & Leaka & Scenario & & & & & & \\
\hline & & & 1 & 2 & 3 & 4 & 5 & 6 & 7 & 8 & 9 & 10 & 11 & 12 & 13 \\
\hline \multirow{4}{*}{$\begin{array}{l}\text { Ruptured } \\
\text { ear drums }\end{array}$} & $\begin{array}{l}\text { Consequence, } \\
\text { max. }^{1}\end{array}$ & $(-)$ & 0.3 & 1.0 & 1.0 & 1.0 & 1.0 & 1.0 & 1.0 & 0.3 & 0.3 & $<10^{-8}$ & $<10^{-8}$ & $8.7 \times 10^{-3}$ & 0.5 \\
\hline & Damage $^{2}$ & [people] & 1.9 & 7.2 & 7.2 & 7.2 & 7.2 & 7.2 & 7.2 & 1.9 & 1.9 & $<10^{-8}$ & $<10^{-8}$ & $6.3 \times 10^{-2}$ & 3.3 \\
\hline & $\begin{array}{l}\text { Individual risk, } \\
\text { max. }^{3}\end{array}$ & [/year] & $3.2 \times 10^{-3}$ & $3.2 \times 10^{-3}$ & $2.9 \times 10^{-6}$ & $7.2 \times 10^{-3}$ & $3.2 \times 10^{-3}$ & $2.9 \times 10^{-6}$ & $7.2 \times 10^{-3}$ & $2.8 \times 10^{-4}$ & $5.1 \times 10^{-7}$ & $<10^{-8}$ & $<10^{-8}$ & $6.6 \times 10^{-6}$ & $1.3 \times 10^{-2}$ \\
\hline & Population risk ${ }^{4}$ & [people/year] & $2.3 \times 10^{-2}$ & $2.3 \times 10^{-2}$ & $2.1 \times 10^{-5}$ & $5.2 \times 10^{-2}$ & $2.3 \times 10^{-2}$ & $2.2 \times 10^{-4}$ & $5.2 \times 10^{-2}$ & $2.0 \times 10^{-3}$ & $3.7 \times 10^{-6}$ & $<10^{-8}$ & $<10^{-8}$ & $4.8 \times 10^{-5}$ & $9.5 \times 10^{-2}$ \\
\hline \multirow{4}{*}{$\begin{array}{l}\text { Blast-wave } \\
\text { fatalities }\end{array}$} & $\begin{array}{l}\text { Consequence, } \\
\text { max. }\end{array}$ & $(-)$ & $4.4 \times 10^{-5}$ & 1.0 & 1.0 & 1.0 & 1.0 & 1.0 & 0.7 & $4.4 \times 10^{-5}$ & $4.4 \times 10^{-5}$ & $<10^{-8}$ & $<10^{-8}$ & $<10^{-8}$ & $3.0 \times 10^{-4}$ \\
\hline & Damage & [people] & $3.2 \times 10^{-4}$ & 6.9 & 7.2 & 7.0 & 7.2 & 7.2 & 5.1 & $3.2 \times 10^{-4}$ & $3.2 \times 10^{-4}$ & $<10^{-8}$ & $<10^{-8}$ & $4.7 \times 10^{-8}$ & $2.2 \times 10^{-3}$ \\
\hline & $\begin{array}{l}\text { Individual risk, } \\
\text { max. }\end{array}$ & [/year] & $5.2 \times 10^{-7}$ & $2.4 \times 10^{-3}$ & $2.8 \times 10^{-6}$ & $5.2 \times 10^{-3}$ & $2.3 \times 10^{-3}$ & $2.8 \times 10^{-6}$ & $3.5 \times 10^{-2}$ & $4.5 \times 10^{-8}$ & $<10^{-8}$ & $<10^{-8}$ & $<10^{-8}$ & $<10^{-8}$ & $6.0 \times 10^{-6}$ \\
\hline & Population risk & [people/year] & $3.8 \times 10^{-6}$ & $1.7 \times 10^{-2}$ & $2.0 \times 10^{-5}$ & $3.7 \times 10^{-2}$ & $1.6 \times 10^{-2}$ & $2.2 \times 10^{-4}$ & $2.6 \times 10^{-2}$ & $3.2 \times 10^{-7}$ & $<10^{-8}$ & $<10^{-8}$ & $<10^{-8}$ & $<10^{-8}$ & $4.4 \times 10^{-5}$ \\
\hline \multirow{4}{*}{$\begin{array}{l}\text { Head-injury } \\
\text { fatalities }\end{array}$} & $\begin{array}{l}\text { Consequence, } \\
\text { max. }\end{array}$ & $(-)$ & $5.2 \times 10^{-5}$ & 1.0 & 1.0 & 0.8 & 0.9 & 0.9 & 0.5 & $5.2 \times 10^{-5}$ & $5.2 \times 10^{-5}$ & $<10^{-8}$ & $<10^{-8}$ & $3.8 \times 10^{-8}$ & $2.7 \times 10^{-4}$ \\
\hline & Damage & [people] & $3.8 \times 10^{-4}$ & 5.9 & 6.9 & 6.1 & 6.8 & 6.8 & 3.3 & $3.8 \times 10^{-4}$ & $3.8 \times 10^{-4}$ & $<10^{-8}$ & $<10^{-8}$ & $2.7 \times 10^{-7}$ & $1.9 \times 10^{-3}$ \\
\hline & $\begin{array}{l}\text { Individual risk, } \\
\text { max }\end{array}$ & [/year] & $6.2 \times 10^{-7}$ & $2.2 \times 10^{-3}$ & $2.7 \times 10^{-6}$ & $4.2 \times 10^{-3}$ & $1.9 \times 10^{-3}$ & $2.6 \times 10^{-6}$ & $2.2 \times 10^{-3}$ & $5.4 \times 10^{-8}$ & $<10^{-8}$ & $<10^{-8}$ & $<10^{-8}$ & $<10^{-8}$ & $5.6 \times 10^{-6}$ \\
\hline & Population risk & [people/year] & $4.5 \times 10^{-6}$ & $1.6 \times 10^{-2}$ & $2.0 \times 10^{-5}$ & $3.2 \times 10^{-2}$ & $1.4 \times 10^{-2}$ & $2.0 \times 10^{-4}$ & $1.6 \times 10^{-2}$ & $3.9 \times 10^{-7}$ & $<10^{-8}$ & $<10^{-8}$ & $<10^{-8}$ & $<10^{-8}$ & $4.1 \times 10^{-5}$ \\
\hline
\end{tabular}

${ }^{1}$ Maximum value of 10-m mesh cell for rupture leak. ${ }^{2}$ Total sum value of all 10-m mesh cells for rupture leak. ${ }^{3}$ Maximum value of 10 -m mesh cell for all leak sizes. ${ }^{4}$ Total sum value of all 10-m mesh cells for all leak sizes. 
The maximum consequence due to heat radiation is nearly 100\% in Scenarios 2-7 (i.e., hydrogen leakage from the pipe connected to the cylinders and compressors in the hydrogen storage process). The individual mortality risk due to heat radiation exceeds $10^{-3}$ per year in Scenarios 2, 4, 5 and 7 . However, the mortality risk due to heat radiation in Scenarios 3 and 6 (i.e., hydrogen leakage directly from the cylinders) is less than $10^{-5}$ per year because the leak frequency is low. Furthermore, the consequence and risk due to heat radiation in Scenarios 8-13 (i.e., hydrogen leakage at dehydrogenation) are less than those for the hydrogen storage process.

Table 6 lists the results for the consequence, damage, and risk due to acute toxicity. The risks of human exposure to atmospheric concentrations of toluene exceeding AEGL-2 and AEGL-3 equivalent human NOAEL are very small in Scenarios 14-21. The maximum individual risk of human exposure to concentrations of MCH and toluene exceeding AEGL-1 equivalent human NOAEL exceeds $10^{-3}$ per year in Scenarios 18 and 21, but the level of the effect is slight.

Table 6. Results for consequence, damage, and risk to people by acute toxicity.

\begin{tabular}{|c|c|c|c|c|c|c|c|c|}
\hline \multirow[t]{2}{*}{ Effect } & \multirow[t]{2}{*}{ Item } & \multirow[t]{2}{*}{ Unit } & \multicolumn{6}{|c|}{ Leakage Scenario } \\
\hline & & & 14 & 1516 & 517 & 18 & 1920 & 21 \\
\hline \multirow{4}{*}{ AEGL-1 } & Consequence, max. ${ }^{1}$ & $(-)$ & 0 & 00 & 0 & 0.5 & $0 \quad 0$ & 0.4 \\
\hline & Damage 2 & [people] & 0 & 00 & 0 & 58.5 & 0 & 29.2 \\
\hline & Individual risk, max. ${ }^{3}$ & [/year] & 0 & $0 \quad 0$ & 0 & $1.3 \times 10^{-3}$ & $0 \quad 0$ & $8.9 \times 10^{-4}$ \\
\hline & Population risk ${ }^{4}$ & [people/year] & 0 & 00 & 0 & 0.12 & $0 \quad 0$ & $5.8 \times 10^{-2}$ \\
\hline \multirow{4}{*}{ AEGL-2 } & Consequence, max. & $(-)$ & 0 & 0 & 0 & 0 & - & - \\
\hline & Damage & [people] & 0 & -0 & 0 & 0 & - & - \\
\hline & Individual risk, max. & [/year] & 0 & -0 & 0 & 0 & - & - \\
\hline & Population risk & [people/year] & 0 & -0 & 0 & 0 & - & - \\
\hline \multirow{4}{*}{ AEGL-3 } & Consequence, max. & $(-)$ & 0 & -0 & 0 & 0 & - & - \\
\hline & Damage & [people] & 0 & -0 & 0 & 0 & - & - \\
\hline & Individual risk, max. & [/year] & 0 & -0 & 0 & 0 & - & - \\
\hline & Population risk & [people/year] & 0 & -0 & 0 & 0 & $-\quad-$ & - \\
\hline
\end{tabular}

${ }^{1}$ Maximum value of 10-m mesh cell for rupture leak. ${ }^{2}$ Total sum value of all 10-m mesh cells for rupture leak.

${ }^{3}$ Maximum value of $10-\mathrm{m}$ mesh cell for all leak sizes. ${ }^{4}$ Total sum value of all $10-\mathrm{m}$ mesh cells for all leak sizes.

\section{Discussion}

For process safety management, Kolluru et al. [23] indicated that the average individual mortality risk level for public should be less than $10^{-6}$ per year and the maximum individual mortality risk for employees should be less than $10^{-4}$ per year. EIHP2 document of risk acceptance criteria for HRSs [24] indicates that the individual mortality risk for employees and customers caused by hydrogen-process related events should not exceed $10^{-4}$ per year. ISO [25] proposes the risk criteria for HRSs as an average individual risk (AIR) less than $10^{-6}$ for vulnerable external populations and an AIR less than $10^{-4}$ for facility users and workers. In this study, the risk criteria were set that the individual mortality risk in the inner side of the station should be less than $10^{-4}$ per year, and the risk to the surrounding residents should be less than $10^{-6}$ per year.

Figure 3 shows the maximum individual mortality risk by each scenario. The individual mortality risk due to explosion is less than $10^{-6}$ per year in Scenarios 1-13, which is a negligible level of concern. The individual mortality risk due to acute toxicity is less than $10^{-6}$ per year in Scenarios 14-21, which is also a negligible level of concern. The individual mortality risk due to heat radiation exceeds $10^{-4}$ per year in Scenarios 2, 4, 5 and 7, and the mortality risk exceeds $10^{-6}$ per year in Scenarios 2-7 and 13 . 


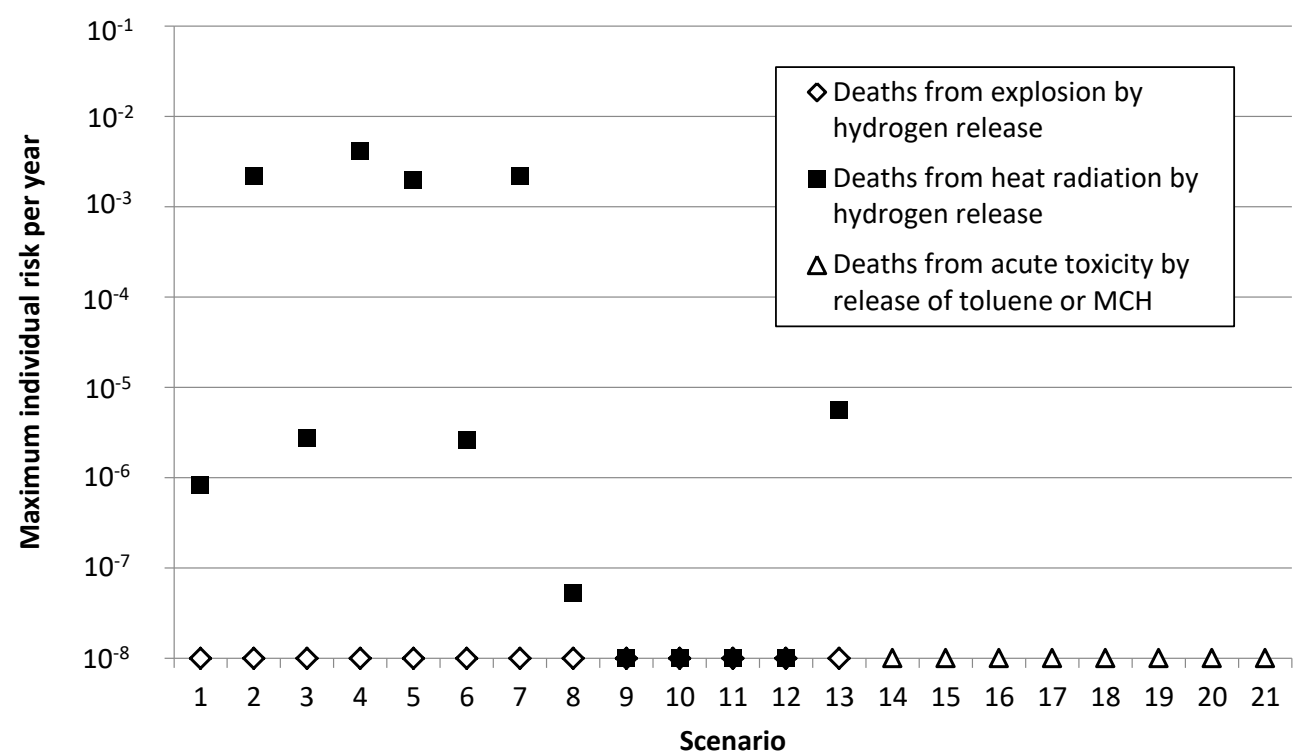

Figure 3. Maximum individual mortality risk in each leakage scenario.

Figure 4 shows the relationship between the distance from release point of hydrogen and individual risk in Scenarios 2, 4, 5 and 7. The result indicates that the mortality risk exceeds $10^{-4}$ per year within the $10 \mathrm{~m}$ distance from the release point of hydrogen. Thus, the individual mortality risk due to heat radiation is not a negligible level of concern in the inner side of the HRS, and the equivalent risk to the surrounding residents is very much smaller.

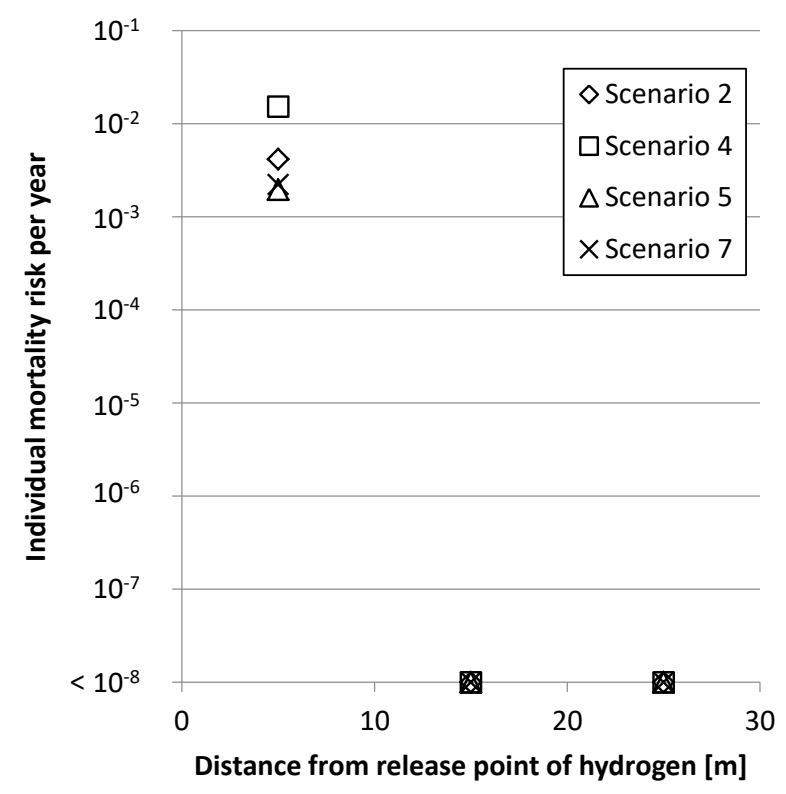

Figure 4. Relationship between the distance from release point of hydrogen and individual mortality risk.

Therefore, the mortality risk to the surrounding residents due to explosion, heat radiation, and acute effects is less than $10^{-6}$ per year, which is a negligible level of concern. Meanwhile, although the mortality risk to workers and customers inside the HRS due to the blast wave and acute toxicity is also less than $10^{-6}$ per year and therefore also poses a negligible level of concern, the mortality risk due to heat radiation in the accident scenarios in which hydrogen leaks from the pipe connected to the cylinders and compressors exceeds $10^{-4}$ per year inside the station, thereby requiring additional steps if a more-detailed risk assessment is needed. 


\section{Conclusions}

This study conducted a screening-level risk assessment of the impairment to human health and life related to hydrogen explosions and chemical releases during the operation of an HRS that uses organic hydride. Twenty-one accident scenarios were identified involving the leakage of hydrogen during the high-pressure hydrogen storage process and dehydrogenation process and of toluene and $\mathrm{MCH}$ during the liquid storage process. The Leak frequency of each leakage scenario was estimated using a hierarchical Bayesian model. Simulations were performed of the blast-wave pressure and heat radiation after a hydrogen leak and of the atmospheric dispersion of evaporated chemicals after leaks of liquid MCH and toluene. Probit functions or threshold values were created for each effect, and the consequences were estimated for each scenario according to leak size. The risks due to explosion, heat radiation, and acute toxicity were estimated by multiplying the consequences by the leak frequency.

As a result, the mortality risk to the surrounding residents in all accident scenarios was less than $10^{-6}$ per year, which is a negligible level of concern. The mortality risk to workers and customers due to the blast wave and acute toxicity inside the HRS upon leakage of hydrogen from the dehydrogenation process and of toluene and $\mathrm{MCH}$ from the liquid storage process was also less than $10^{-6}$ per year, again a negligible level of concern. However, the mortality risk due to heat radiation in the accident scenarios involving hydrogen leakage from the pipe connected to the cylinders and compressors in the high-pressure hydrogen storage process exceeded $10^{-4}$ per year inside the HRS, thereby requiring additional steps if a more-detailed risk assessment is needed. In conclusion, we revealed that the individual mortality risk is negligible in the accident scenarios in the liquid storage process and the dehydrogenation process uniquely installed in HRSs that use organic hydride.

In future work, we will conduct a detailed risk assessment in the accident scenarios in the hydrogen storage process installed in all HRSs. We intend to use event-tree analysis to estimate accident frequencies, and to conduct hazard assessment by arranging grid points for analysis at smaller intervals than those used in the present study. Measures based on risk criteria should also be investigated by conducting QRA using the consequence, damage, and occurrence-probability data presented herein.

Author Contributions: Conceptualization, K.T.; methodology, K.T., K.Y. and K.O.; software, K.Y. and T.S.; validation, K.T., K.Y., T.K. and T.S.; formal analysis, K.T., K.Y., T.K. and T.S.; investigation, T.K.; resources, K.T., K.Y. and K.O.; data curation, K.T. and K.Y.; writing-original draft preparation, K.T.; writing-review and editing, T.K., K.Y. and K.O.; visualization, K.T.; supervision, K.T.; project administration, K.T.; and funding acquisition, K.T.

Funding: This work was supported by the Council for Science, Technology and Innovation (CSTI) through its Cross-ministerial Strategic Innovation Promotion Program (SIP), and "Energy Carrier" (funding agency: Japan Science and Technology Agency (JST)).

Conflicts of Interest: The authors declare no conflict of interest.

\section{References}

1. Nakayama, J.; Misono, H.; Sakamoto, J.; Kasai, N.; Shibutani, T.; Miyake, A. Simulation-based safety investigation of a hydrogen fueling station with an on-site hydrogen production system involving methylcyclohexane. Int. J. Hydrogen Energy 2017, 42, 10636-10644. [CrossRef]

2. Li, Z.; Pan, X.; Ma, J. Quantitative risk assessment on 2010 Expo hydrogen station. Int. J. Hydrogen Energy 2011, 36, 4079-4086.

3. Sun, K.; Pan, X.; Li, Z.; Ma, J. Risk analysis on mobile hydrogen refueling stations in Shanghai. Int. J. Hydrogen Energy 2014, 39, 20411-20419. [CrossRef]

4. LaChance, J. Risk-informed separation distances for hydrogen refueling stations. Int. J. Hydrogen Energy 2009, 34, 5838-5845. [CrossRef]

5. Kikukawa, S.; Yamaga, F.; Mitsuhashi, H. Risk assessment of hydrogen fueling stations for 70 MPa FCVs. Int. J. Hydrogen Energy 2008, 33, 7129-7136. [CrossRef] 
6. Okada, Y.; Saito, M.; Makabe, T. Development of dehydrogenation catalyst for hydrogen storage and transportation system by the organic chemical hydride method. J. Hydrogen Energy Syst. 2006, 31, 8-13. (In Japanese)

7. Okada, Y.; Sasaki, E.; Watanabe, E.; Hyodo, S.; Nishijima, H. Development of dehydrogenation catalyst for hydrogen generation in organic chemical hydride method. Int. J. Hydrogen Energy 2006, 31, 1348-1356. [CrossRef]

8. Biniwale, R.B.; Rayalu, S.; Devotta, S.; Ichikawa, M. Chemical hydrides: A solution to high capacity hydrogen storage and supply. Int. J. Hydrogen Energy 2008, 33, 360-365. [CrossRef]

9. Shukla, A.A.; Gosavi, P.V.; Pande, J.V.; Kumar, V.P.; Chary, K.V.R.; Biniwale, R.B. Efficient hydrogen supply through catalytic dehydrogenation of methylcyclohexane over $\mathrm{Pt} /$ metal oxide catalysts. Int. J. Hydrogen Energy 2010, 35, 4020-4026. [CrossRef]

10. Tsunemi, K.; Yoshida, K.; Yoshida, M.; Kato, E.; Kawamoto, A.; Kihara, T.; Saburi, T. Estimation of consequence and damage caused by an organic hydride hydrogen refueling station. Int. J. Hydrogen Energy 2017, 42, 26175-26182. [CrossRef]

11. Sandia National Laboratories. Analysis to Support Development of Risk-Informed Separation Distances for Hydrogen Code and Standards. Available online: https:/ / energy.sandia.gov/wp-content/uploads / 2018/05/SAND2009-0874-Analyses-to-Support-Development-of-Risk-Informed-Separation-Distancesfor-Hydrogen-Codes-and-Standards.pdf (accessed on 31 October 2018).

12. Kihara, T.; Makino, R.; Ono, K.; Saburi, T.; Kubota, S.; Tsunemi, K.; Wada, Y. Bayesian Estimation of Leak Frequency for Organic Hydride Hydrogen Refueling Stations. J. Jpn. Soc. Saf. Eng. 2017, 56, 2-11. (In Japanese)

13. Sandia National Laboratories. Early-Stage Quantitative Risk Assessment to Support Development to Codes and Standard Requirements for Indoor Fueling of Hydrogen Vehicles. Available online: https: / / www.sandia.gov/ \{\}kgroth/publicationfiles/SAND2012-10150.pdf (accessed on 31 October 2018).

14. The High Pressure Gas Safety Institute of Japan. Accident Database of High Pressure Gas. (In Japanese). Available online: http://www.khk.or.jp/activities/incident_investigation/hpg_incident/incident_db.html (accessed on 9 February 2018).

15. Hazardous Materials Safety Techniques Association. Integrated Information System for Hazardous Materials. (In Japanese). Available online: https:/ / www.khk-syoubou.info/sougou/ (accessed on 31 October 2018).

16. University of Cambridge. The BUGS Project. Available online: https://www.mrc-bsu.cam.ac.uk/software/ bugs/the-bugs-project-winbugs / (accessed on 31 October 2018).

17. Yamatosangyo Co. Ltd. Spec of Excess Flow Stop Valve, Catalog for Gas Supplier Equipment for Hydrogen Station. Available online: http:/ / www.e-yamato.co.jp/data/catalog/5/HEF.SAFETYH2.pdf (accessed on 31 October 2018).

18. Yoshida, K.; Yoshida, M. Estimation of health risks to residents chronically exposed to an organic hydride and its dehydrogenated substance from a hydrogen station. Environ. Sci. 2018, 31, 164-177. (In Japanese)

19. Van den Bosch, C.J.H.; Twilt, L. Damage caused by heat radiation. In Methods for the Determination of Possible Damage to People and Objects Resulting from Release of Hazardous Materials, 1st ed.; Committee for the Prevention of Disasters: Voorburg, The Netherlands, 1992; pp. 1-60. ISBN 9-5307-052-4.

20. Merx, W.P.M. The consequences of explosion effects on humans. In Methods for the Determination of Possible Damage to People and Objects Resulting from Release of Hazardous Materials, 1st ed.; Committee for the Prevention of Disasters: Voorburg, The Netherlands, 1992; pp. 1-43. ISBN 9-5307-052-4.

21. United States Environmental Protection Agency. Acute Exposure Guideline Levels for Airborne Chemicals. Available online: https: / www.epa.gov / aegl (accessed on 13 November 2018).

22. National Research Council. Acute Exposure Guideline Levels for Selected Airborne Contaminants; National Academies Press: Washington, DC, USA, 2014; pp. 1-474. ISBN 978-0-309-30096-4.

23. Stricoff, R.S. Safety risk analysis and process safety management. In Risk Assessment and Management Handbook: For Environmental, Health, and Safety Professionals; Kolluru, R., Steven, M., Bartell, S., Pitblado, R., Stricoff, S., Eds.; McGraw-Hill, Inc.: New York, NY, USA, 1995; pp. 8.1-53. ISBN 0-07-035987-3. 
24. European Integrated Hydrogen Project. Risk Acceptance Criteria for Hydrogen Refuelling Stations. Available online: http:/ / www.eihp.org/public/documents / acceptance_criteria_for_H2-refuelling_stations_FEB2003. pdf (accessed on 31 October 2018).

25. International Organization for Standardization. Gaseous_Fuelling Stations_Part 1: General Requirements; ISO/DIS 19880-1; International Organization for Standardization: Geneva, Switzerland, 2018; pp. 1-176. 